\title{
Teatro y ciencia cognitiva. Entrevista con Rick Kemp
}

\section{Sol Alonso}

Universidad Nacional de Río Negro, Argentina

salonso@unrn.edu.ar

Fecha de recepción: 06/03/2020. Fecha de aceptación: 30/03/2020.

\begin{abstract}
Resumen
Entrevista realizada en octubre de 2018 al actor, director, profesor e investigador teatral Rick Kemp acerca de por qué los avances en la ciencia cognitiva pueden ser aplicados al trabajo del actor. Miembro del Seminario Global de Neurociencia y Arte de Salzburgo, Rick Kemp es Profesor de Teatro y director del área de Actuación y Dirección del Departamento de Danza y Teatro de la Universidad de Indiana de Pensilvania. Entre sus publicaciones se destacan: The Routledge Companion to Theater, Performance and Cognitive Science (2019), Embodied Acting: what neuroscience tells us about performance (2012) y The Routledge Companion to Jacques Lecoq (2016).
\end{abstract}

Palabras clave: Kemp, ciencia cognitiva, neurociencia, actuación, pedagogía teatral

\section{Theatre and Cognitive Science. Interview with Rick Kemp}

\begin{abstract}
Interview conducted in October 2018 with the actor, director, professor and researcher Rick Kemp about how recent discoveries in the field of cognitive science can be applied to performance. Kemp is Professor of Theater and Head of Acting and Directing in the Department of Theater and Dance at Indiana University of Pennsylvania. He is also a fellow of the Salzburg Global Seminar on Neuroscience and Art. His publications include The Routledge Companion to Theater, Performance and Cognitive Science (2019), Embodied Acting: what neuroscience tells us about performance (2012) and The Routledge Companion to Jacques Lecoq (2016).
\end{abstract}

Keywords: Kemp, cognitive science, neuroscience, acting, teaching 


\section{- En su vasta experiencia como actor y director ha trabajado con diversas técnicas y estilos (la técnica LeCoq, el clown, los clásicos). En su libro Embodied Acting reconoce que a través de los años lo ha guiado un objetivo fundamental...}

Kemp: Mi principal objetivo es afectar a la audiencia, es poder hacer un teatro vital y accesible y descubrir cómo las palabras pueden integrarse al movimiento para crear respuestas viscerales en el público. Creo que para poder involucrar a la audiencia se requiere de ella una respuesta afectiva o emocional hacia lo que ven en el escenario; siempre he buscado realizar esto en mi trabajo profesional. En mis primeros años de carrera me dediqué a trabajar la comedia con la técnica del clown y, en este caso, hay un claro indicador en cuanto a si la audiencia está o no conectada con lo que sucede en el escenario, porque se están riendo o no se están riendo. Pero, más adelante, cuando me dediqué a trabajos más variados con el realismo, Shakespeare y otros estilos, la conexión con la audiencia no resultaba tan clara. Desde entonces siempre he buscado unir el parlamento a la acción. Cuando encontré estos principios en la neurociencia me di cuenta de que esta disciplina le daba una base teórica a algo que, tanto yo como otros actores, habíamos experimentado fenomenológicamente.

\section{- ¿Cuál fue su primera intuición en cuanto a relacionar estos procesos a los estudios realizados en el campo de la neurociencia? ¿Cómo se desarrolló su investigación?}

Kemp: Mi propia curiosidad me provocó continuar investigando en esta dirección. De hecho, el primer libro que cayó en mis manos en relación a este tema fue Inteligencia Emocional de Daniel Goleman. Esto me llevó a Antonio Damasio y a leer más y más en el campo de la neurociencia. La investigación que realicé hasta el momento tiene que ver con indagar en los descubrimientos existentes de la neurociencia. Definitivamente, el primer libro que escribí estaba basado en esto. En cuanto a realizar investigaciones de naturaleza experimental mediante la creación de estudios, lo estoy haciendo en mi universidad enfocándome en los procesos de la empatía. De momento, en mi universidad no tenemos máquinas de IRMF (imagen por resonancia magnética funcional) o las redes EEG (electroencefalograma) que se colocan en la cabeza de las personas. Debido a esto, hay cierto tipo de investigaciones que no puedo realizar. En consecuencia, el principal tipo de investigación que realizamos actualmente es mediante la utilización de cuestionarios que realizamos a grupos invitados. No creo que esto sea suficiente, pero hasta que pueda asociarme al departamento de psicología que tiene el tipo de equipamiento que mencioné anteriormente es lo que podemos hacer.

\section{- ¿Cómo se ha modificado su práctica como actor, director y pedagogo a partir de sus investigaciones experimentales?}

Kemp: Tanto en mi enseñanza como en mi rol como director y actor, el nexo más importante entre el conocimiento que he adquirido, entre la neurociencia y la práctica, es el poner el foco en acciones definibles. En mi libro menciono que entiendo que hay acciones primarias para los actores y con esto me refiero a que están basadas en acciones físicas simples. Por ejemplo: agarrar, dar, aceptar, rechazar. Estas acciones están a un nivel más fundacional de la experiencia que acciones más complejas, como, por ejemplo, convencer o persuadir. Enfoqué mi trabajo como actor, director y pedagogo en acciones que tengan una clara expresión física, una clara raíz física. Y una de las cosas en las que estoy trabajando actualmente es en encontrar grupos de acciones. Por ejemplo, en pensar en cuáles son las acciones directas, las acciones que van directamente hacia la persona con la cual uno está interactuando ¿Cuáles 
son las acciones que son indirectas? ¿Cuánta fuerza uno implica en una acción? ¿Hay una forma de comprender las acciones desde las categorías de Laban de peso, tiempo y espacio? Y también estoy notando que hay una gran similitud entre el análisis de Laban y el de Jacques Lecoq, quien habla de que la dinámica del teatro está compuesta por tiempo, espacio y fuerza. Yo añadiría intención a este trío. Sin embargo, pienso que cualquiera sea la intención de un personaje, esta va a ser expresada en tiempo y espacio, que a su vez son grados de la fuerza.

\section{- ¿Cómo surge la imaginación en el trabajo del actor con las acciones? ¿Cómo entiende que opera la consciencia, el estado consciente del actor, sobre los procesos involucrados en la actuación como la imaginación, la memoria, el pensamiento y la acción?}

Kemp: Todavía entiendo que la imaginación se dispara rápidamente a través de la acción. Algunas personas tienen la cualidad de que, al leer un texto, inmediatamente tienen una fuerte conexión imaginaria con el mundo ficcional que describen las palabras, pero esto no le pasa a todo el mundo. Algunas personas no ven inmediatamente imágenes mentales cuando leen un texto ni necesariamente tienen una respuesta emocional hacia él. Entonces, en el trabajo que he hecho hasta ahora, el enfocarse en la acción ayuda al actor a unir el texto a la imaginación y a la emoción. En cuanto a la conciencia, no creo poder ofrecer una definición, porque pienso que el concepto está siendo arduamente debatido en el mundo filosófico y científico. Creo que obviamente tenemos que tener una percepción del mundo que aparentemente se encuentra más allá de nuestro cuerpo; entonces, ese sería uno de los rasgos o características de la conciencia. Podría imaginar que ser consciente de uno mismo como un ser con agencia, la habilidad de hacer, es también una característica de la conciencia. Y luego creo que también implica la habilidad de distinguir entre la naturaleza de las actividades dentro del entorno que uno experimenta, entre las experiencias que podrían llamarse cotidianas y las ficcionales. Entonces, volvemos a la idea de la imaginación, creo que los actores debemos necesariamente saber distinguir lo ficcional de lo real. Para entender esto, los actores están haciendo un acto consciente de imaginación para involucrarse en las circunstancias de la ficción, pero no puedo decir demasiado de la conciencia en ese contexto.

-Le consulto sobre el rol de la conciencia en el trabajo actoral, porque tanto Stanislavski como Yoshi Oida hablan sobre una doble naturaleza del estado consciente del actor en la escena. Stanislavski escribe sobre la diferencia entre "la perspectiva del actor" y "la perspectiva del personaje", como un proceso de desdoblamiento del intérprete. Oida, por su parte, introduce el concepto de "el observador" como un aspecto del actor que observa lo que él mismo está interpretando.

Kemp: Desde que escribí Embodied Acting, obviamente he estado leyendo mucho más y mis ideas se han desarrollado y modificado. Hay un autor llamado Daniel Kahneman, quien ha hablado acerca del sistema 1 y del sistema 2 de conciencia. El sistema 1 está, para ponerlo muy simple, relacionado con las respuestas reflejas a estímulos sensoriales; y el sistema 2 está relacionado a la conciencia del pensamiento. Científicos y filósofos escribiendo sobre este campo mencionan dos tipos de procesamiento: top down processing y bottom up processing. Pienso que el fenómeno de la conciencia dual puede tener que ver con una rápida alteración del grado de foco en relación a la conciencia sensorial y en el pensamiento conceptual. Podemos pensar que el estado 
consciente se compone de dos sistemas básicos y que en determinado momento el porcentaje de atención consciente que uno tiene sobre los datos sensoriales puede ser más alto que el porcentaje que uno tiene sobre el pensamiento conceptual. Una forma de entender la conciencia dual es que existe una veloz fluctuación del porcentaje o del balance entre estos dos sistemas. Entonces, tenemos la información sensorial y el procesamiento conceptual. Ahora hay un concepto bastante bien establecido llamado "procesamiento predictivo". En este proceso, el pensamiento conceptual es comparado a la información sensorial en el cerebro y el pensamiento conceptual realiza una predicción sobre el significado de la información sensorial; luego, si esta predicción no corresponde a la información sensorial, entonces se hace otra predicción hasta que esta coincide con la información sensorial. Sobre este tema hay un muy buen libro de Andy Clark que se llama Surfing Uncertainty.

\section{-En los últimos quince años se ha demostrado que la neurociencia y otras disciplinas de la ciencia cognitiva tienen mucho para ofrecer al campo de la investigación teatral. ¿Piensa que la psicología, la filosofía, la neurociencia y la lingüística podrían nutrirse de la práctica y teoría teatral?}

Kemp: Esto es algo en lo que estoy muy interesado de momento, porque creo que el teatro y el entrenamiento actoral tienen mucho que ofrecer a otros campos: neurociencia, filosofía, psicología, desarrollo pedagógico. Y una de las dificultades en cuanto a vincular al teatro como un área de investigación para los científicos es la variabilidad de los términos que utilizamos, que además no están relacionados a términos y conceptos de disciplinas como la psicología. Creo que una de las primeras cosas que necesitamos es la creación de un glosario de vocabulario que pueda ayudar a los científicos a comprender lo que la gente de teatro quiere decir con determinados términos y comportamientos. Muy poco ha sido estudiado en teatro desde una perspectiva científica y creo que una de las principales razones es que el proceso científico requiere de una reducción de variables para conducir un experimento, y el contexto del entrenamiento de actores o de actores en situación de actuación es muy complejo y está lleno de variables. Por este motivo es muy difícil, por ejemplo, realizar una comparación entre un actor haciendo una cosa y otro actor haciendo otra. Para los científicos es un mundo muy desorganizado para intentar trabajar en él. Pero yo escribí un artículo, en realidad un capítulo para un libro sobre la memoria, que está específicamente dirigido a los científicos. En ese escrito les digo que miren al teatro, que miren cómo los actores memorizan tanto los textos como sus comportamientos y cómo hacen que todo parezca espontáneo. Es una especie de gran laboratorio potencial para investigar. Pienso que el teatro tiene mucho que ofrecer y que, poco a poco, algunos científicos están comenzando a entenderlo. Creo que cuanto más busquemos comunicarnos con ellos, más fácil les resultará comprender lo que el teatro tiene para ofrecerles.

\section{-En esta dirección, está por publicar un nuevo libro...}

Sí; es una antología que incluye capítulos encargados especialmente a investigadores que en los últimos quince años han estado integrando las investigaciones de la ciencia cognitiva a estudios teatrales y de la escena.

\section{-Muchas gracias por su tiempo.}

